\title{
Organoleptic Acceptability, Selected Nutrient Content and Physicochemical Characteristics of Coconut Neera on Storage
}

\author{
Priya Ramaswamy ${ }^{1}$ and Lalitha Ramaswamy ${ }^{2}$ \\ 1. Guest Faculty, Department of Home Science, Mother Teresa Women's University Research and Extension Centre, Coimbatore - 2, \\ India \\ 2. Department of Nutrition and Dietetics, PSG College of Arts and Science, Coimbatore 641 0014, India
}

\begin{abstract}
Neera is the sweet juice or sap, obtained by tapping the unopened inflorescence of the coconut palm and is rich in minerals. In order to improve the nutritional quality and acceptability of the product a trial was carried out to combine aloe cubes and strawberry flavour with neera. Aloe vera is a flavourless and translucent white soft gel with bland taste and rich in phytonutrients and electrolytes. Standard neera (SN) was prepared with neera alone (100\%) and compared against experimental neera (EN) prepared with neera $(87 \%)$, aloe vera cubes $(10 \%)$ and strawberry extract $(3 \%)$. The processed neera was packed in presterilized bottles and stored at $5{ }^{\circ} \mathrm{C}$. Organoleptic acceptability and storage stability study were carried out every week. Physicochemical characteristics and selected nutrient content were analysed on 0th day and at the end of storage period. Overall acceptability of EN (8.5 \pm 0.53$)$ was higher than SN $(8 \pm 0.82)$ on 0th day and over different storage periods. There was a gradual decrease in the organoleptic scores of both EN and SN on storage and it was unacceptable on 56th day of storage. The sodium, potassium and vitamin C content of EN were significantly higher than SN. The TSS of SN and EN were $14 \pm 0{ }^{\circ} \mathrm{B} / 100 \mathrm{~mL}$ and $15.6 \pm 0{ }^{\circ} \mathrm{B} / 100 \mathrm{~mL}$ respectively on 0 th day. Significant $(p \leq 0.01)$ increase in the microbial count in EN was noticed on storage.
\end{abstract}

Key words: Neera, aloe vera cubes, strawberry extract, organoleptic evaluation, nutrient analysis, physiochemical characteristics, microbial count.

\section{Introduction}

Neera, otherwise called sweet toddy is a sap extracted from inflorescence of coconut palm. It is sweet, oyster white, and translucent. Neera is a delicious health drink and a rich source of natural sugars, minerals and vitamins. It contains 16 kinds of amino acids and various vitamins such as vitamin $\mathrm{C}$, vitamin B complex, especially nicotinic acid and minerals (potassium, magnesium, zinc and iron) [1]. It has less calorific value, apart from being sweet and delicious and also functions as a good digestive agent [2].

The unopened inflorescence is used for tapping. The female flowers inside the spathe (about $60(\mathrm{~cm})$

Corresponding author: Priya Ramaswamy, guest faculty, research field: food processing and food product development. long) cause a swelling at the base, and this indicates the appropriate stage for tapping (Fig. 1a). The inflorescence selected for tapping is tied around with a strong coir or to prevent it from bursting (Fig. 1b). The technique of neera collection is shown in Fig. 1c. After 4-5 days of stroking, $7-10 \mathrm{~cm}$ of the tip is sliced-off and in a day or two sap starts oozing from the cut surface.

A coconut palm can yield, on an average 2 litres of neera per day, which may go even up to 4.5 litres per day based on the health of the palm [8]. Neera is also used as raw material for the production of syrup or honey, granulated brown sugar, alcoholic beverages, vinegar and acetic acid [9, 10]. To preserve and extend the shelf life of neera, heat preservation techniques such as pasteurization are used [13]. 

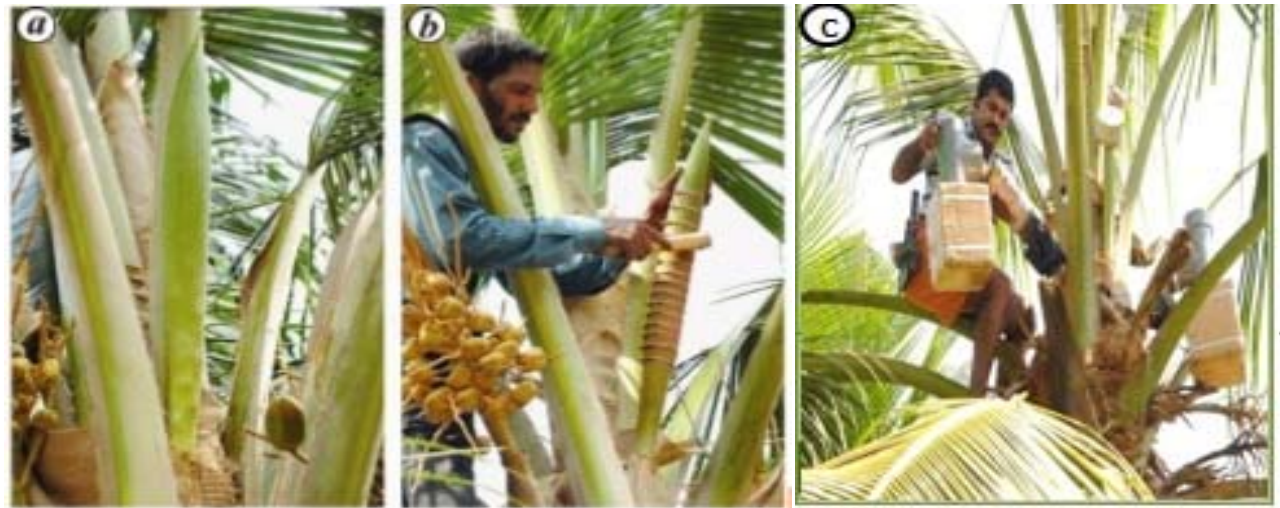

Fig. 1 (a) Ideal spadix with swollen base; (b) Stroking spadix using a mallet week; (c) Neera tapping by a technician.

Neera is rich in all the minerals, further to improve the nutritional quality of the product a trial was carried out to combine aloe cubes in the neera. Aloe vera is a flavourless and translucent white soft gel with bland taste, it combines with all types of fruit juices. It is rich in antioxidants. It blends well with neera without altering its taste. To impart a bity texture and unique taste, aloe vera was added to neera in the form of cubes rather as juice. In the light of the above, this research has been taken up with the following objectives:

- To formulate neera with aloe vera cubes and strawberry flavour and to assess the range of acceptability of the neera through sensory evaluation over different storage periods;

- To compare the selected nutrient content and physicochemical characteristics of neera initially and finally during the storage period;

- To assess the storage stability of neera over different storage periods.

\section{Materials and Methods}

\subsection{Sources of Raw Materials}

Neera processing was carried out at Coconut Development Board (CDB), Cochin. Neera was collected from the farm, maintained by $\mathrm{CDB}$, Cochin. The ingredients required for neera processing were neera, aloe vera cubes and strawberry extract. Strawberry was purchased from a reputed departmental store in Coimbatore. Aloe vera was obtained farm fresh.

\subsection{Preparation of Aloe Vera Cubes}

Aloe vera leaves were plucked from the plant, the sides trimmed and outer skin removed. The central gel portion was separated and washed several times. Aloe vera gel was cut into cubes and pasteurized for 20 minutes at $80{ }^{\circ} \mathrm{C}$. Aloe vera consists of $99.3 \%$ water and the remaining $0.7 \%$ is a mix of more than 75 essential nutrients including natural vitamins, minerals, enzymes, protein and amino acids. It has a diverse mixture of complex phytonutrients that have immune boosting and astringent properties in addition to natural coagulators, pain inhibitors and cell growth stimulators [6]. Aloe vera has been demonstrated to enhance the immune system response to cancer, promote the growth of new and healthy cells and reduce the overall viral load within the body thereby revitalizing the body in its fight against the cancer [5].

\subsection{Preparation of Strawberry Extract}

Strawberry was washed and put into the juice maker to obtain the extract and cooked with equal amount of sugar at $80{ }^{\circ} \mathrm{C}$ for 20 minutes.

\subsection{Formulation and Standardisation of Neera}

Two variants of the neera were prepared namely standard neera (SN) and experimental neera (EN). Standard neera was prepared as per the procedure of 
CDB. Experimental neera was processed with aloe vera cubes and strawberry extract (Table 1).

\subsection{Processing of Neera}

Neera is highly susceptible to natural fermentation within a few hours of extraction from palms. Once fermented, it transforms to toddy with $4 \%$ alcohol. Neera is collected twice a day, in the early morning and in the evening. To prevent the fermentation of neera an anti-fermentable solution (AFS - developed by $\mathrm{CDB}$ ) was added in the can used for collecting the neera from the spadix. $10 \mathrm{~mL}$ of AFS was added for every 1 litre of the neera that exudates from the tree.

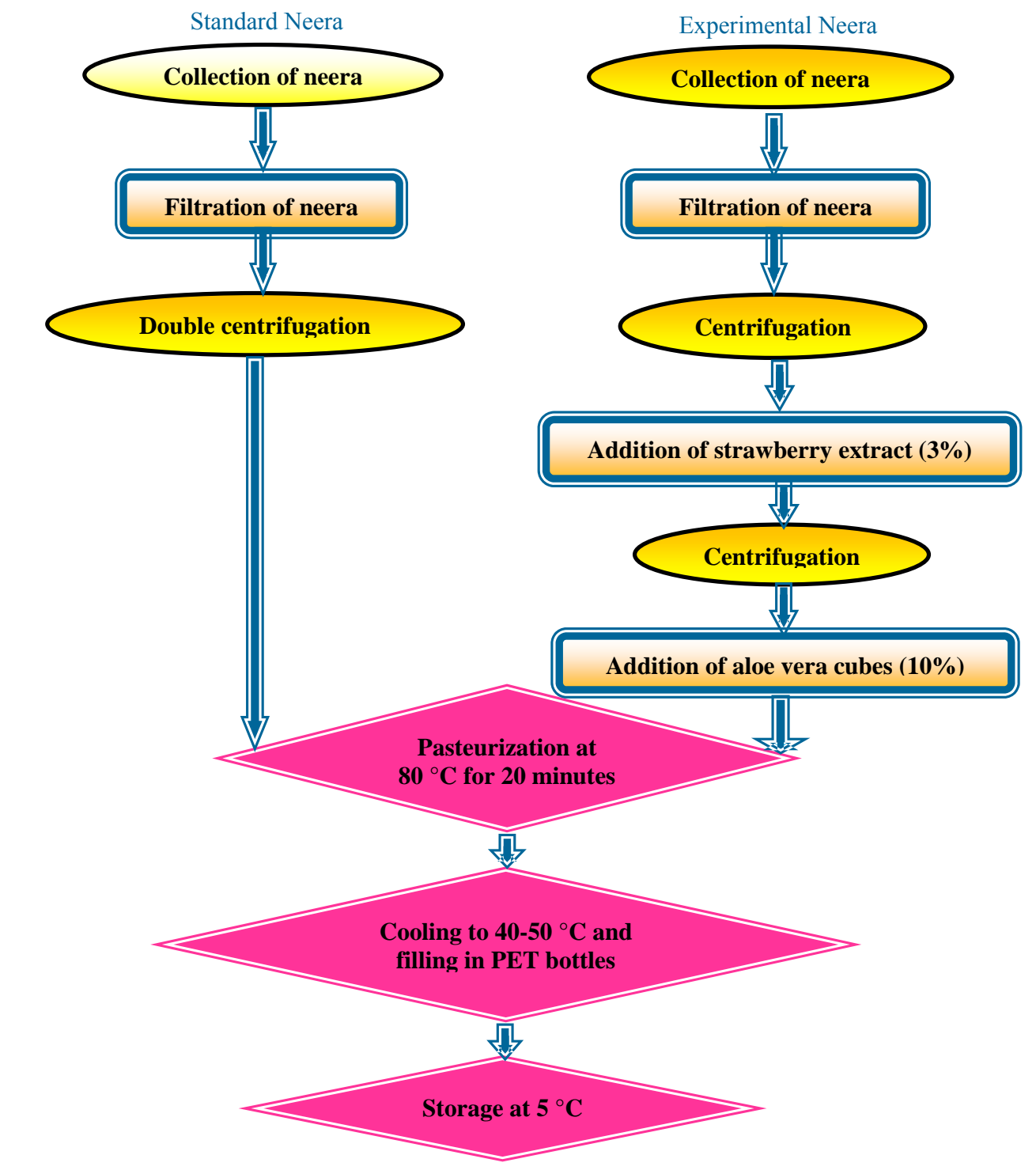
in Fig. 3.

Fresh sap has slightly alkaline $\mathrm{pH}$ (7.5-8, minor variation from tree to tree). Addition of AFS helps to maintain the $\mathrm{pH}$ at around 5.1-5.3 and also acts as a preservative medium for the neera up to 6 months of storage at $5{ }^{\circ} \mathrm{C}$. The processing steps of $\mathrm{SN}$ and $\mathrm{EN}$ were given in Fig. 2. The formulated neera are shown

Table 1 Quantification of ingredients for $100 \mathrm{~mL}$ of neera.

\begin{tabular}{lll}
\hline Ingredients & SN (plain) & $\begin{array}{l}\text { EN (strawberry flavour } \\
\text { with aloe vera cubes) }\end{array}$ \\
\hline Neera & $100 \mathrm{~mL}$ & $87 \mathrm{~mL}$ \\
Aloe vera cubes & - & $10 \mathrm{~g}$ \\
Strawberry extract & - & $3 \mathrm{~mL}$ \\
\hline
\end{tabular}

Strawberty extract -1 mL

Fig. 2 Processing of neera. 


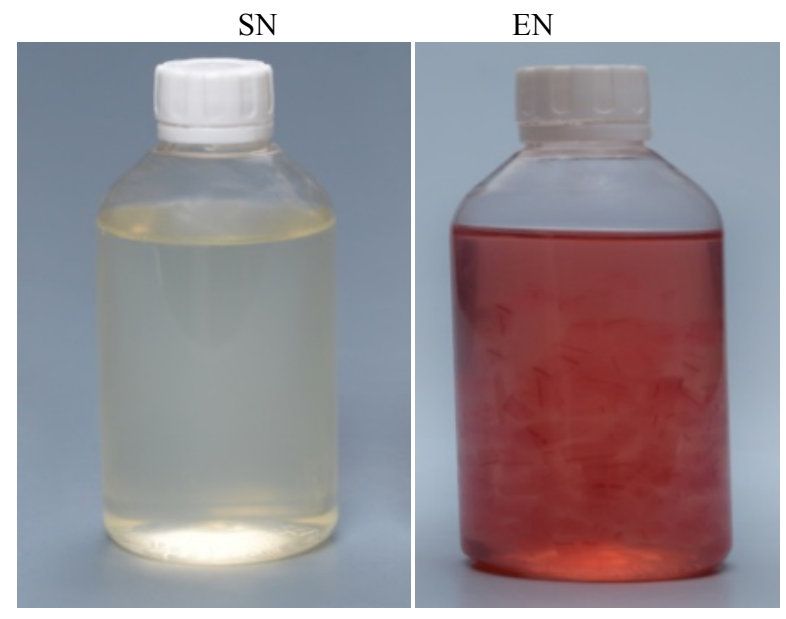

Fig. 3 Formulated neera.

\subsection{Organoleptic Evaluation of Neera}

The product acceptability of neera was assessed using a 9 point hedonic scale for the quality factors such as colour, flavour, taste, consistency and overall acceptability by a panel consisting of ten semi trained judges. The organoleptic test was carried out for the standard and experimental neera on the 0th day and then periodically every week up to 56 days. The storage was terminated on 56th day since fermented flavour emanated from the neera samples.

\subsection{Nutrient Analysis of Neera}

Samples of SN and EN were analysed in triplicates for energy (differential calculation, AOAC, 1980), iron (thiocynate colorimetry method, Sadashivm and Manickam, 1991), calcium (titrimetric method, AOAC, 1980), sodium and potassium (flame photometer, Sadashivm and Manickam, 1991), and vitamin C (2,6- dichlorophenol indophenol method, Ranganna, 1995) on the 0th day and 56th day.

\subsection{Physicochemical Characteristics of Neera}

SN and EN were analysed in triplicates for the physico chemical characteristics namely $\mathrm{pH}$ (using digital pH meter, AOAC 1990), titrable acidity (Ranganna, 1986), TSS (using hand refractometer) and total sugar (Lane and Eynon's method, Ranganna, 1995) on 0th day and 56th day.

\subsection{Microbial Analysis of Neera}

The total microbial count was analysed on 0th day and then periodically every week up to 56 days.

\subsection{Statistical Analysis}

The results obtained from the study were interpreted using statistical tools. Tools such as $t$-test and ANOVA were performed.

- test between organoleptic scores, nutrient analysis, physicochemical analysis and microbial count.

- ANOVA between organoleptic scores and microbial count.

\section{Results and Discussion}

\subsection{Mean Organoleptic Scores of Neera}

\subsubsection{Colour}

The mean scores obtained by SN and EN for colour on 0th day were $8.2 \pm 0.63$ and $8.4 \pm 0.52$ respectively (Fig. 4). The mean score of EN had increased to $8.5 \pm$ 0.53 on 28th day and decreased gradually at the end of the storage period. A decreasing trend in the colour of both the samples was noticed on storage, and the scores of SN $(8 \pm 0.67)$ remained higher than EN (8.3 \pm 0.48 )

\subsubsection{Consistency}

Both SN and EN had obtained the same mean scores of $8.5 \pm 0.53$ on 0 th day. The mean scores remained the same on 56th day for both the samples. Panellists reported that the consistency was good in both the samples till the end of the storage period.

\subsubsection{Taste}

The mean score for taste of EN $(8.6 \pm 0.52)$ was higher than SN $(8.3 \pm 0.67)$ on 0th day. Decreasing trend in the taste score of both the samples was observed and on 56th day the score of EN was higher (SN $-6.2 \pm 0.79, \mathrm{EN}-7.5 \pm 0.71$ ). The taste of EN was most appreciated by the panellists due to the addition of aloe vera cubes which imparted a characteristic bite in the mouth, and thus scored higher than $\mathrm{SN}$ both on 

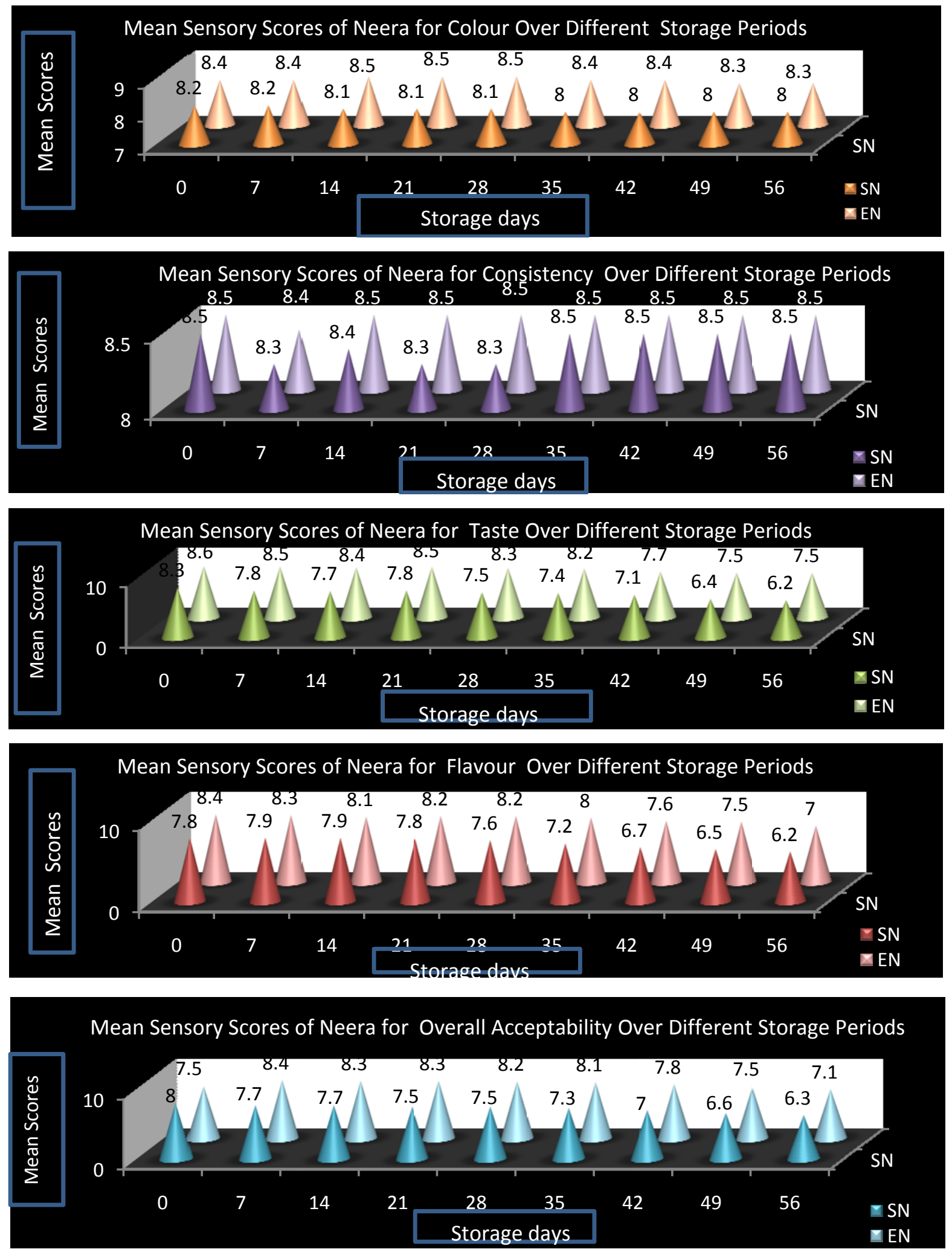

Fig. 4 Mean organoleptic scores of neera. 
the 0th day and at the end of the storage period.

\subsubsection{Flavour}

The mean scores for flavour of SN and EN were 7.8 \pm 0.63 and $8.4 \pm 0.52$ respectively on 0th day. Addition of strawberry extract to EN was a key factor for receiving highest score than SN. On storage decreasing trend in the flavour of both variants was observed and on 56th day the score of SN and EN were $6.2 \pm 0.63$ and $7 \pm 0.67$ respectively, yet the mean score of EN was higher than SN. The fermented flavour of SN on storage was disliked by the panellists. However, in EN, the unique flavour of neera and aloe vera cubes was masked by the addition of strawberry extract.

\subsubsection{Overall Acceptability}

The mean score for overall acceptability of EN (8.5 $\pm 0.53)$ was higher than $\mathrm{SN}(8 \pm 0.82)$ on 0th day. During storage it was observed that overall sensory quality profile of neera had decreased gradually and on 56th day, yet the mean score of EN was higher than $\mathrm{SN}$. As reported in the previous research on aloe vera and aonla based beverage the sensory characteristics, i.e. appearance, colour, flavour, taste and overall acceptability showed a decreasing trend during the storage [11].

\subsection{Nutrient Content of Neera}

\subsubsection{Energy}

The energy content of EN $(57.43 \pm 0.06 \mathrm{kcal} / 100$ $\mathrm{mL})$ was significantly $(p \leq 0.01)$ higher than $\mathrm{SN}$ $(53.43 \pm 0.12 \mathrm{kcal} / 100 \mathrm{~mL})$ on the 0th day and $56 \mathrm{th}$ day (EN $-58.50 \pm 0.01 \mathrm{kcal}$ per $100 \mathrm{~mL}, \mathrm{SC}-56.44 \pm$ $0.06 \mathrm{kcal} / 100 \mathrm{~mL}$ ) (Table 2). On storage, the energy value had increased significantly $(p \leq 0.01)$ in both $\mathrm{SN}$ and EN.

\subsubsection{Calcium}

The calcium content of the neera ranged from 78.07 $\pm 0.12 \mathrm{mg} / 100 \mathrm{~mL}$ to $84.17 \pm 0.29 \mathrm{mg} / 100 \mathrm{~mL}$ on 0 th day, with the highest seen in SN. On comparing the calcium level of SN and EN on 0th day and 56th day, significant $(p \leq 0.01)$ decrease was observed.

\subsubsection{Iron}

The iron content of SN $(18.13 \pm 0.23 \mathrm{mg} / 100 \mathrm{~mL})$ was significantly $(p \leq 0.01)$ higher than EN $(13.33 \pm$ $0.58 \mathrm{mg} / 100 \mathrm{~mL}$ ) on 0 th day and 56th day (SN -16.13 $\pm 0.23 \mathrm{mg} / 100 \mathrm{~mL}, \mathrm{EN}-11.23 \pm 0.40 \mathrm{mg} / 100 \mathrm{~mL}$ ). On storage, the iron level of both $\mathrm{SN}$ and EN had significantly $(p \leq 0.01)$ reduced. The iron level of neera in the present work remained high compared to the results which had reported 0.049-0.058 mg/100 $\mathrm{mL}$ of iron in the freshly collected coconut sap [4].

\subsubsection{Sodium}

The sodium content was $10.1 \pm 0.17 \mathrm{mg} / 100 \mathrm{~mL}$ and $22.03 \pm 0.06 \mathrm{mg} / 100 \mathrm{~mL}$ for $\mathrm{SN}$ and $\mathrm{EN}$ respectively on 0th day. EN was statistically significant $(p \leq 0.01)$ against $\mathrm{SN}$ on 0 th day and 56th day. On storage, the decrease in SN was only marginal and was not statistically significant. In EN significant $(p \leq 0.01)$ decrease was observed. However the values obtained in the present study were less compared to the values (Sodium -69.4-117.5 g/100 mL of fresh coconut sap) [2].

Table 2 Nutrient content of neera.

\begin{tabular}{|c|c|c|c|c|c|c|c|c|c|}
\hline \multirow{2}{*}{ S.No } & \multirow{2}{*}{$\begin{array}{l}\text { Nutrients } \\
\text { per } 100 \mathrm{~mL}\end{array}$} & \multicolumn{2}{|c|}{ 0th day } & \multicolumn{2}{|c|}{ 56th day } & \multirow{2}{*}{$\begin{array}{l}\text { 0th day } \\
\text { SN VS EN }\end{array}$} & \multirow{2}{*}{$\begin{array}{l}\text { 56th day } \\
\text { SN VS EN }\end{array}$} & \multirow{2}{*}{$\begin{array}{l}\text { SN } \\
\text { 0th day } \\
\text { VS 56th } \\
\text { day }\end{array}$} & \multirow{2}{*}{$\begin{array}{l}\text { EN } \\
\text { 0th day } \\
\text { VS s 56th } \\
\text { day }\end{array}$} \\
\hline & & SN & EN & SN & EN & & & & \\
\hline 1 & Energy (kcal) & $53.43 \pm 0.12$ & $57.43 \pm 0.06$ & $56.44 \pm 0.06$ & $58.50 \pm 0.01$ & $53.666^{* *}$ & $64.639^{* *}$ & $40.662 * *$ & $31.941 * *$ \\
\hline 2 & Calcium (mg) & $84.17 \pm 0.29$ & $78.07 \pm 0.12$ & $80 \pm 0$ & $72.1 \pm 0.17$ & $33.982 * *$ & $79.000 * *$ & $25.000 * *$ & $49.646^{* *}$ \\
\hline 3 & Iron (mg) & $18.13 \pm 0.23$ & $13.33 \pm 0.5$ & $16.13 \pm 0.23$ & $11.23 \pm 0.40$ & $13.370 * *$ & $18.233^{* *}$ & $10.607 * *$ & $5.161 * *$ \\
\hline 4 & Sodium (mg) & $10.1 \pm 0.17$ & $22.03 \pm 0.06$ & $10 \pm 0$ & $20.03 \pm 0.06$ & $113.210 * *$ & $301.000 * *$ & $1.000^{\mathrm{NS}}$ & $42.426^{* *}$ \\
\hline 5 & Potassium (mg) & $117.67 \pm 0.58$ & $124.17 \pm 0.29$ & $110 \pm 0$ & $119.1 \pm 0.17$ & $17.441^{* *}$ & $91.000^{* *}$ & $23.000 * *$ & $26.068 * *$ \\
\hline 6 & Vitamin C (mg) & $55.07 \pm 0.12$ & $60.1 \pm 0.17$ & $53 \pm 0.17$ & $54.77 \pm 0.06$ & $41.880 * *$ & $16.760 * *$ & $17.196^{* *}$ & $50.596 * *$ \\
\hline
\end{tabular}

** Significance at $p \leq 0.01$, NS-Not significant. 


\subsubsection{Potassium}

The substitution of aloe vera cubes had significantly $(p \leq 0.01)$ increased the potassium level of $\mathrm{EN}$ $(124.17 \pm 0.29 \mathrm{mg} / 100 \mathrm{~mL})$ when compared to $\mathrm{SN}$ $(117.67 \pm 0.58 \mathrm{mg} / 100 \mathrm{~mL})$ on 0 th day and the same persisted on 56th day. On storage the loss of potassium level was significant $(p \leq 0.01)$ in both $\mathrm{SN}$ and EN. These results are in fair agreement with Wang [14] who also reported that potassium and chloride concentration appeared to be excessive in aloe vera juice in comparison to most plant products whereas the sodium content was found lesser in quantity.

\subsubsection{Vitamin C}

The vitamin C level of EN $(60.1 \pm 0.17 \mathrm{mg} / 100 \mathrm{~mL})$ was significantly higher than $\mathrm{SN}$ (55.07 \pm 0.12 $\mathrm{mg} / 100 \mathrm{~mL}$ ) on 0 th day and 56 th day. A decrease was noticed in both the samples on storage, but the loss was higher in EN than the standard one. On comparing the levels between the storage periods ( $p \leq$ 0.01 ) a decrease was observed in both the samples. Whereas, Xia et al. [15] had recorded lower value of vitamin C (20.4 mg/L) in the fresh coconut sap.
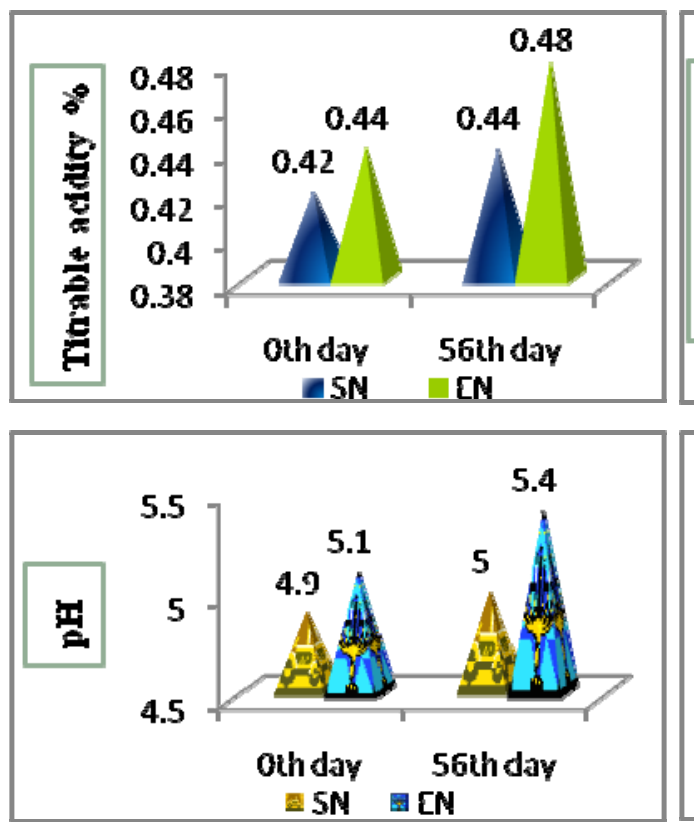

\subsection{Physicochemical Characteristics of Neera}

\subsubsection{Titrable Acidity}

The titrable acidity of neera was $0.42 \% \pm 0.01 \%$ in $\mathrm{SN}$ and $0.44 \% \pm 0.01 \%$ in $\mathrm{EN}$ on 0th day (Fig. 5). Increasing trend in the titrable acidity was noticed in both the samples on storage. On 56th day, the titrable acidity of EN was significantly higher than SN. On comparing the acidity levels of the 0th and 56th day, the increase in EN was significant $(p \leq 0.01)$ statistically, whereas in SN it was not significant (Table 3). Similar increase in the acidity levels was recorded by Ysidor et al. [16] for fresh coconut sap during 120 hours of storage $(0.26 \pm 0.04$ to $1.85 \pm$ $0.09 \mathrm{~g} / 100 \mathrm{~mL})$.

\subsubsection{Total Sugar}

Total sugar of SN $(9 \% \pm 0 \%)$ was lower than EN $(11 \% \pm 0 \%)$ on 0 th day. On 56th day the total sugar in both the samples had increased (SN -9.82 \pm $0.03 \% / 100 \mathrm{~mL}, \mathrm{EN}-11.38 \% \pm 0.03 \%$ ) and in $\mathrm{EN}$ it was significantly higher than SN. Significant $(p \leq 0.01)$ increase in the total sugars of SN and EN during the storage was observed. The total sugar content of SN in

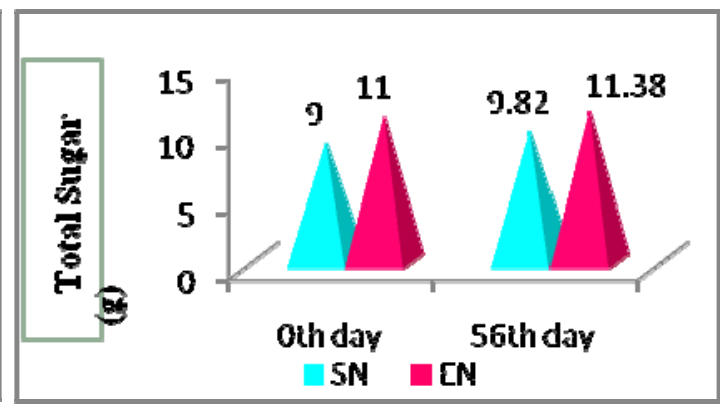

Fig. 5 Results of physicochemical characteristics of neera.

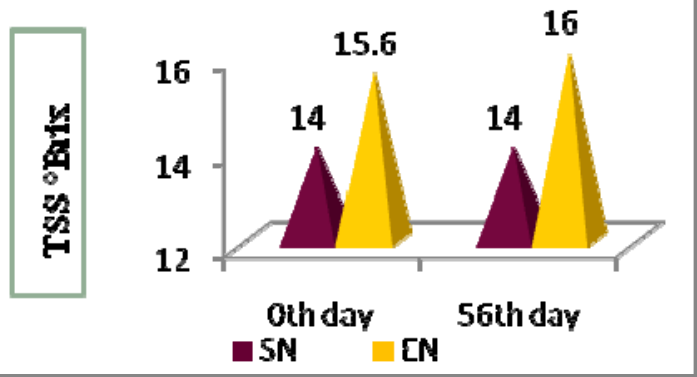


Table 3 “ $t$ ” values comparing physicochemical characteristics of neera.

\begin{tabular}{|c|c|c|c|c|c|}
\hline S. No & $\begin{array}{l}\text { Physicochemical Characteristics } \\
\text { Per } 100 \mathrm{~mL}\end{array}$ & $\begin{array}{l}\text { 0th day } \\
\text { SN VS EN }\end{array}$ & $\begin{array}{l}\text { 56th day } \\
\text { SN VS EN }\end{array}$ & $\begin{array}{l}\text { SN } \\
0 \text { th day VS 56th } \\
\text { day }\end{array}$ & $\begin{array}{l}\text { EN } \\
\text { 0th day VS 56th } \\
\text { day }\end{array}$ \\
\hline 1 & Titrable acidity (\%) & $3.578^{\mathrm{NS}}$ & $11.000 * *$ & $3.500^{\mathrm{NS}}$ & $7.071 * *$ \\
\hline 2 & Total Sugar (\%) & - & $60.049 * *$ & $41.000 * *$ & $23.000 * *$ \\
\hline 3 & $\operatorname{TSS}\left({ }^{\circ} \mathrm{B}\right)$ & - & - & - & - \\
\hline 4 & $\mathrm{pH}$ & - & - & - & - \\
\hline
\end{tabular}

** Significance at $p \leq 0.01$, NS-Not significant.

- $t$ cannot be computed because the standard deviations of both groups are 0 .

Table 4 Microbial count of neera.

\begin{tabular}{llll}
\hline Days & SN & EN & "t" value \\
\hline 0th day & X $10^{5} \mathrm{cfu} / \mathrm{gm}$ & $\mathrm{X} 10^{5} \mathrm{cfu} / \mathrm{gm}$ & \\
7th day & - & - & \\
14th day & - & - & \\
21st day & - & $0.43 \pm 0.06$ & $1.414^{\mathrm{NS}}$ \\
28th day & $0.37 \pm 0.06$ & $0.93 \pm 0.06$ & $4.243^{\mathrm{NS}}$ \\
35th day & $0.73 \pm 0.06$ & $1.23 \pm 0.15$ & $0.354^{\mathrm{NS}}$ \\
42nd day & $1.27 \pm 0.06$ & $2.63 \pm 0.06$ & $10.286^{* *}$ \\
49th day & $1.87 \pm 0.12$ & $2.73 \pm 0.21$ & $5.687^{* *}$ \\
56th day & $1.77 \pm 0.21$ & $3.27 \pm 0.31$ & $5.154^{* *}$ \\
\hline
\end{tabular}

**Significance at $p \leq 0.01$, NS-Not significant.

Table 5 Results of ANOVA comparing microbial count of SN and EN between 0th day and 56th day.

\begin{tabular}{llllll}
\hline One way ANOVA for SN & \multicolumn{5}{l}{} \\
\hline Source & Sum of squares & $\mathrm{df}$ & Mean square & $\mathrm{F}$ & Sig. \\
Between groups & 18.499 & 8 & 2.312 & 189.189 & $* *$ \\
Within groups & 0.220 & 18 & 0.012 & & \\
Total & 18.719 & 26 & & & $* *$ \\
\hline One way ANOVA for EN & & & & 270.711 & \\
\hline Between groups & 40.907 & 8 & 5.113 & & \\
Within groups & 0.340 & 18 & 0.019 & & \\
Total & 41.247 & 26 & & & \\
\hline
\end{tabular}

**Significance at $p \leq 0.01$, NS-Not significant.

the present study was less compared to the results (10.8-16.50 g/100 $\mathrm{mL}$ in fresh coconut sap) [2].

\subsubsection{TSS}

The initial TSS was $14 \pm 0{ }^{\circ} \mathrm{B} / 100 \mathrm{~mL}$ for $\mathrm{SN}$ and $15.6 \pm 0{ }^{\circ} \mathrm{B} / 100 \mathrm{~mL}$ for $\mathrm{EN}$. This value was less compared to the value (15.2-19.7) [13]. On storage the TSS remained the same for $\mathrm{SN}$ and a marginal increase was observed in $\mathrm{EN}(16 \pm 0)$. Whereas, N'guessan [16] had reported decrease in TSS in fresh coconut sap during short storage of 120 hours, with means varying from $16.31 \% \pm 0.55 \%$ to $14.65 \% \pm$ $0.41 \%$, but in the present study TSS was found to increase in EN with the advancement of storage.

\subsection{4 $\mathrm{pH}$}

The $\mathrm{pH}$ of $\mathrm{SN}$ was lower than EN on 0th day (SN $-4.9 / 100 \mathrm{~mL} \pm 0$ and $\mathrm{EN}-5.1 \pm 0 / 100 \mathrm{~mL}$ ). On storage the value had increased in both the samples ( $\mathrm{SN}-5 \pm$ 0/100 $\mathrm{mL}$ and $\mathrm{EN}-5.4 \pm 0 / 100 \mathrm{~mL}$ ). The $\mathrm{pH}$ value of $\mathrm{SN}$ was similar to the levels (4.7) in fresh coconut sap [7]. 


\subsection{Microbial Count of Neera}

No microbial colonies were seen up to 14th day of storage (Table 4). On 21st day the count of EN increased than $\mathrm{SN}$, but was not significant. The same trend was observed on 28th day. On 35th day the microbial count of $\mathrm{SN}$ raised than $\mathrm{EN}$, but not significant. Significant $(p \leq 0.01)$ increase in the microbial count in EN was noticed from 42nd day and this persisted till the end of the storage period. Similarly, no bacterial growth initially and on 120th day the count was $4.00 \times 10^{6} \mathrm{cfu} / \mathrm{g}$ in room temperature and $2.00 \times 10^{6} \mathrm{cfu} / \mathrm{g}$ in refrigerated temperature in spiced tender coconut water [12]. The shelf life remains a limiting factor for the valorisation of the coconut sap. Indeed, the rich nutritional composition of the sap leads logically to its fast spoilage. The deterioration is caused by the microorganisms associated with both environmental and hygienic conditions of the sap production [3].

Results of one way ANOVA (Table 5) showed significant increase in the microbial count between 0th day and 56th day of both SN and EN.

\section{Conclusion}

Sensory quality revealed that aloe vera cubes and strawberry extract could be successfully incorporated with neera up to the ratio of 87:10:3 (neera: aloe cubes: strawberry extract). The formulated neera was organoleptically acceptable up to a storage period of two months. The sodium, potassium and vitamin $\mathrm{C}$ content was increased in EN, as aloe vera cubes contain high amount of these nutrients. All the physicochemical characteristics stand high for EN than $\mathrm{SN}$ and this is solely due to the addition of aloe vera cubes and strawberry extract. The results of microbial quality revealed that EN had significantly high microbial count towards the end of the storage period. Neera could be promoted as natures' bio health drink for its delicious taste and is also rich source of phytonutrients. Neera could become a nutritious drink offering a healthy alternative to aerated beverages. Neera can also be promoted as a sports drink.

\section{Acknowledgement}

This work was supported by Smt. Annie Eapen, Chemist, Coconut Development Board Institute of Technology (CIT) South Vazhakulam, Aluva, for her assistance in getting permission from the Director of $\mathrm{CDB}$ and guidance in neera processing at Aluva pilot plant, Cochin, India.

\section{References}

[1] Aalbersberg, B., Rohinee, S., and Praveen, R. 1997. "Nutrient Analysis of Coconut Toddy." Trop. Sci. 37 (3): 160-3.

[2] Devdas, R. P., Sundari, K., and Susheela, A. 1969. "Effects of Supplementation of Two School Lunch Programmes with Neera on the Nutritional Status of Children." J. Nutr. Diet 6: 29-36.

[3] Borse, B. B., Rao, L. J. M., Ramalakshmi, K., and Raghavan, B. 2007. "Chemical Composition of Volatiles from Coconut Sap (Neera) and Effect of Processing." Food Chemistry 101: 877-80.

[4] Augustine, J., and Hebbar, K. B. 2014. Coco Sap Chiller: A New Device for the Collection of Fresh. Hygienic and Unfermented Kalparasa (neera), Patent filed, 5, p. 972.

[5] Gage, D. 2005. Aloe Vera: Natures Soothing Healer.

[6] Hastings, and Kellie. 2007. "Aloe Vera and Its Incredible Compounds." Ezine Articles 11. http://ezinearticles.com/?Aloe-Vera-And-Its-Incredible-C ompounds\&id=773184.

[7] Kalaiyarasi, K., Sangeetha, K., and Rajarajan, S. 2013. "A Comparative Study on the Microbial Flora of the Fresh Sap from Cut Inflorescence and Fermented Sap (toddy) of Borrassus flabellifer Linn (Palmyrah tree) and of Cocos nucifera Linn (Coconut tree) to Identify the Microbial Fermenters." International Journal of Research in Pure and Applied Microbiology 3 (3): 43-7.

[8] Muralidharan, K., and Nair Deepthi, S. 2013. "Coconut Neera." The Hidden Unexplored Treasure, Indian Coconut Journal, Theme article 7 (4): 4.

[9] Nair Sunil, A., Mejosh Jose, Regi, J., and Thomas, R. V. 2013. "Production of Neera." Indian Coconut Journal 7 (4): 25-6.

[10] Purnomo, H. 1992. "Sugar Components of Coconut Sugar in Indonesia." Asian Food J. 7 (4): 200-1.

[11] Sasikumar, R. 2013. "Effect of Processing on Physiochemical and Sensory Parameters of Low Calorie 


\section{Characteristics of Coconut Neera on Storage}

Therapeutic RTS Beverage Blend of Aloe Vera and Aonla Fruit Using Artificial Sweeteners." As. J. Food Ag-Ind. 6 (06): 337-46.

[12] Sindumathi, G., and Amutha, S. 2015. "Development of Spiced Tender Coconut Water Ready to Serve Beverage." International Journal of Science and Research 4 (10): 233-6.

[13] Swamy Siddharameswara, G. M. 2013. "Coconut Neera Production and Processing in Karnataka." Indian Coconut Journal 7 (4): 30-3.

[14] Wang, Y. T. 1993. "Bases of Aloe Certification." Aloe Today 27-9.
[15] Xia, Q. Y., Li, R., Zhao, S. L., Chen, W. J., Chen, H., Xin, B., Huang, Y. L., and Tang, M. M. 2011. "Chemical Composition Changes of Post-harvest Coconut Inflorescence Sap During Natural Fermentation.” African Journal of Biotechnology 10 (66): 14999-5005.

[16] N'guessan, Y. K., Jean-Louis, K. K., Roger, K. B., Rachel, A. R., Joelle, O. D. M., Emmanuel, I. A., and Marius, B. G. H. 2015. "Changes in Physicochemical Parameters during Storage of the Inflorescence Sap Derived from Four Coconut (Cocos nucifera L.) Varieties." American Journal of Experimental Agriculture 5 (4): 352-65. 